\title{
Toward an Account of Gender IDENTITY
}

\author{
KATHARINE JENKINS \\ University of Nottingham
}

\begin{abstract}
Although the concept of gender identity plays a prominent role in campaigns for trans rights, it is not well understood, and common definitions suffer from a problematic circularity. This paper undertakes an ameliorative inquiry into the concept of gender identity, taking as a starting point the ways in which trans rights movements seek to use the concept. First, I set out six desiderata that a target concept of gender identity should meet. I then consider three analytic accounts of gender identity: the dispositional account, the self-identification account, and the normrelevancy account. I argue that only the norm-relevancy account can meet all six desiderata. Finally, I defend the norm-relevancy account from three objections: that it is cis-normative, that it has problematic implications regarding trans women, and that it entails that some people do not have the gender identity they take themselves to have.
\end{abstract}

\section{Introduction: The Folk Concept of Gender Identity}

The concept of gender identity has entered into increasing circulation in recent years, principally due to increasing awareness of gender diversity and to the greater prominence of campaigns for trans rights. The concept plays an important role in these campaigns in two main ways. Firstly, it plays a crucial definitional role: being trans is typically defined as 'having a gender identity that is different from the gender one was assigned at birth'. Correspondingly, being cis is typically defined as 'having a gender identity that is the same as the gender one was assigned at birth'. Thus, the concept of gender identity is used to define both trans identity and, by extension, trans rights. Secondly, campaigns for trans rights paradigmatically call for gender identity to be used as the basis for people's access to, and treatment within, gendered social spaces-for example,

Contact: Katharine Jenkins <katharine.jenkins@nottingham.ac.uk> 
for trans people to be able to use the bathroom facilities that correspond to their gender identity, and to be addressed in ways that reflect their gender identity. Although it is important to recognise that campaigns for trans rights are by no means homogenous, the use of the concept of gender identity in these two ways is very widely shared. ${ }^{1}$

The most widely accepted definition of gender identity characterises it as 'a sense of oneself as a man, woman, or some other gender'. ${ }^{2}$ It will be immediately apparent to the reader that this 'folk' definition is not complete until some account is offered of what it is to have a sense of oneself as 'a man, woman, or some other gender'. This is where the folk definition begins to run into difficulties: no such account is usually offered as part of the definition, and there is no consensus on what kind of account might be appropriate. The difficulty is compounded by the fact that many people who use the language of gender identity hold an understanding of what it is to be a 'man, woman, or some other gender' that is highly unsuited to supplementing the folk definition of gender identity. This is the view that gender terms such as 'man' and 'woman' ought to be understood in terms of gender identity: to be a man is to identify as a man (or, to have a male gender identity); ${ }^{3}$ to be a woman is to identify as a woman (or, to have a female gender identity); to be a non-binary person is to identify as nonbinary (or, to have a non-binary gender identity), and so on. The combination of this view with the folk definition of gender identity gives rise to a circularity: someone who asks what it means to say that a certain person 'has a female gender identity' will be told that it means that that person has a sense of herself 'as a woman' - but if the questioner then asks what a 'woman' is, they will be told that a woman is 'a person with a female gender identity'. Thus, the questioner is none the wiser as to what it means to have a female gender identity.

I do not intend here to take a stance on whether or not gender terms should be used, in general, primarily to refer to gender identity. ${ }^{4}$ The point I wish to make is that even someone who thinks that gender terms should in general refer to gender identity must, on pain of circularity, allow that in the context of the defi-

1. See, e.g., https://transequality.org/; https://srlp.org/; http://www.hrc.org/explore/topic/ transgender; $\quad$ https://www.stonewall.org.uk/our-work/campaigns/come-out-trans-equality; https://www.amnesty.org.uk/issues/lgbti-rights.

2. See, e.g., http://www.hrc.org/resources/sexual-orientation-and-gender-identity-terminology-and-definitions; http://eige.europa.eu/rdc/thesaurus/terms/1179; http://www.yogyakartaprinciples.org/introduction/. Sometimes it is further specified that this sense is 'inner' or 'personal', and that it may not be the same as the gender the person is perceived as having or the gender they were assigned at birth.

3. In this paper I will use the phrase ' $X$ identifies as a man/woman' and ' $X$ has a male/female gender identity' interchangeably, taking them to mean exactly the same thing. This is purely for reasons of grammatical convenience; I am not, e.g., using 'male/female' as sex terms rather than gender terms.

4. I have argued elsewhere (Jenkins 2016) that they should. 
nition of gender identity, the idea of having a sense of oneself 'as a man, woman or some other gender' must be explained without reference to gender identity. The current lack of any widely accepted explanation of this idea, and the resulting circularity in the folk concept of gender identity, is a problem from the point of view of trans rights campaigners. It would, from that perspective, be beneficial to be able to explain what gender identity is to people who do not already understand the concept, in order that they can participate in movements for trans rights in an informed way.

The present moment, at which the concept of gender identity is rapidly permeating public consciousness, presents a particularly good opportunity for establishing a widespread and sound understanding. In order to take advantage of this opportunity, however, it is necessary to have a clear and non-circular definition of gender identity. Although, as we have seen, the folk concept of gender identity is not adequate in this regard, the fact that there is widespread agreement on at least some of the work that the concept of gender identity ought to be able to do offers a promising starting point for expanding on the folk definition. Put simply, the thought is this: since we know something about how trans rights movements need to use the concept of gender identity, we can assess various possible ways of extending the folk definition in terms of how well suited they are to those uses, with a view to selecting the one that is best able to do the required work. This is my aim in this paper.

This approach is one that has been the subject of recent discussion within analytic philosophy, where it is known as prescriptive conceptual analysis (Burgess \& Plunkett 2013), or as ameliorative inquiry (Haslanger 2012c). Burgess and Plunkett distinguish between two different kinds of projects of conceptual analysis: (i) descriptive, and (ii) prescriptive. In the former, descriptive project, we seek to discover how a concept is currently being employed, including what type or kind in the world (if any) it refers to; by contrast, in the prescriptive project we seek to identify which concept we ought to use given our purposes. Haslanger's method of ameliorative inquiry, developed in her work on gender and race, is an example of prescriptive analysis. In ameliorative inquiry, we seek to identify which concept (or concepts) ${ }^{5}$ would be most helpful for us to use given certain political aims. The concept that an ameliorative inquiry results in is termed the 'target concept'. My aim, then, can be more precisely stated as follows: to identify the target concept of gender identity, given the shared aims of trans rights movements, where this is understood as a prescriptive endeavour. ${ }^{6}$

In adopting this aim, I do not intend to commit myself to the claim that only

5. I have argued (Jenkins 2016) that ameliorative inquiries may 'branch' so as to deliver multiple target concepts, no one of which would be able to fulfil all the goals of the inquiry by itself.

6. Note that this is different from the descriptive endeavour of establishing what concept (or concepts) of gender identity is (or are) being used in trans rights movements. 
one concept of gender identity is needed. The phenomenon is a complex one, and it may well be that different concepts are needed to capture different aspects of it. This pluralism is compatible with the idea that it is strategically useful for trans rights movements to adopt a single definition of gender identity if one can be found that fits their purposes. It is to this latter idea only that I am committed. I will treat it as an open possibility that no definition exists that can do all the work that trans rights movements need it to do, in which case it might be necessary to adopt multiple definitions, perhaps distinguished by different terminology.

I begin by exploring in more detail the work that gender identity needs to do in trans rights movements so as to arrive at a set of six desiderata for a target concept of gender identity. I then assess the three existing accounts of gender identity in the analytic philosophical literature relative to these desiderata. I argue that one, which I term 'the norm-relevancy account', can, in a slightly modified form, meet all of the desiderata, and is therefore a good candidate for the target concept of gender identity. Finally, I defend the norm-relevancy account from three objections.

Before I embark on this task, two observations about my approach are in order. Firstly, note that I am simply aiming to establish which concept of gender identity is best able to do the work that trans rights movements, as they currently exist, need it to do. In other words, I am taking the aims of trans rights movements as a starting point for my inquiry. Given the development of the concept of gender identity with reference to the experiences of trans people and the importance of the concept in contemporary struggles for trans rights, this is a natural enough way to approach an ameliorative inquiry on this topic. It is not, however, without potential critics. Some feminists have claimed that feminist considerations entail that the concept of gender identity should be rejected altogether as confused and harmful (for a striking example of this position, see Jeffreys 2014). These claims have been robustly countered by those working from a transfeminist perspective (Bettcher 2009; 2014; Koyama 2006; Lester 2017; Serano 2016). Feminists such as Jeffreys can be interpreted as suggesting, firstly, that feminist aims should motivate the ameliorative inquiry into gender identity, and, secondly, that an ameliorative inquiry motivated in that way will yield the conclusion that no concept of gender identity is required at all. Arguing against the claims of feminists such as Jeffreys is beyond the scope of this article. Although I am fully convinced of the appropriateness of the aims of the trans rights movements, I make no claim to have justified those aims here. I merely seek to establish the concept of gender identity that is required to advance those aims.

Secondly, it must be acknowledged that in bringing the resources of analytic philosophy to bear on gender identity I am adopting an unusual approach to the topic. Although there is a substantial theoretical literature on gender identity in fields such as gender studies and trans studies (see, e.g., Namaste 2000; 
Prosser 1998; Stone 2006; Stryker 1994) this topic has only recently begun to receive attention within analytic philosophy (Andler 2017; Bettcher 2017; Jenkins 2016; McKitrick 2015). The appeal of adopting an approach informed by analytic philosophy is that, as we have seen, analytic philosophy has many resources to offer when it comes to conceptual analysis. By contrast, the strong influence of postmodernist and poststructuralist approaches on gender studies and trans studies means that the latter are typically more focused on phenomenological and deconstructionist investigations than on conceptual analysis, and are thus less likely to be aiming at, and so less likely to yield, a clear and non-circular definition of gender identity. Let me be clear that in my opinion there is room for a wide variety of different and valuable investigations into gender identity. In undertaking conceptual analysis of gender identity I intend merely to investigate the benefits that this approach, which is under-explored in this context, can bring, and not to denigrate existing work on that topic which employs different methods.

\section{Desiderata for a Target Concept of Gender Identity}

What little work there is on gender identity in analytic philosophy has suffered from a striking lack of clarity as to whether it is descriptive or prescriptive in nature. My own work is no exception; although I have previously set out a definition of gender identity as part of an ameliorative inquiry into the concept woman (Jenkins 2016), I did not make it clear whether the definition of gender identity I offered was intended to be ameliorative/prescriptive, or descriptive. Similarly, both McKitrick (2015) and Bettcher (2017) recommend their respective definitions of gender identity for use without explicitly stating whether or not they are intended as target concepts or as concepts that capture current usage. Accordingly, there is much work to be done in terms of establishing how an ameliorative inquiry into gender identity should proceed.

In order to carry out an ameliorative project, it is first necessary to select a set of political aims that are to guide the project. As I have already made clear, the aims guiding the ameliorative project that I am undertaking in this paper are the aims of trans rights movements, which I take to be twofold: promoting the rights of trans people, and countering transphobia. The next task is to establish how these aims translate into specific desiderata for a target concept. In order to do this, it is necessary to look in more detail at the kind of work the concept of gender identity is being required to do in trans rights movements, and at the kind of features it must have in order to do this work well. Accordingly, in this section I set out six desiderata for a target concept. The first three are based fairly directly on the claims made by trans rights campaigners about gender identity, and the 
latter three rely to a greater extent on my own reasoning about what features a concept would need to have in order to do this work.7

As already mentioned, one of the main claims of trans rights movements is that trans people (and indeed everyone else) are entitled to be able to move through social space as members of their identified gender. For example, a trans woman should be able to access women-only spaces such as bathrooms, and should be addressed and described using female-specific language where relevant. $^{8}$ In the philosophical literature this claim has been supported by Stephanie Julia Kapusta (2016), who has argued that misgendering - failing to treat people as members of the gender with which they identify - causes psychological harms such as shame, anxiety, and depression; moral harms such as the undermining of self-respect; and political harms, such as oppression and domination (see also Bailey, Ellis, \& McNeil 2014; Bettcher 2007; 2009).

The claim that misgendering causes harm is an empirical claim and will not be upheld by a definition of gender identity alone. ${ }^{9}$ However, in order to fully support trans rights movements' claim that trans people should be treated as members of their identified genders, it is necessary to supplement the claim that misgendering causes harm with a further claim about the nature of the link with such harm. This is because one might think that misgendering is wrong because it causes harm, whilst thinking that these harms only follow due to misconceptions or weaknesses on the part of the individual. Clearly, the claims of trans rights movements would be substantially weakened if they depended on the idea that trans people who are misgendered only suffer harm on the basis of their own disproportionate responses - an idea that I believe practically all trans rights campaigners would reject. Rather, the strongest case would rest on the premise that the harms suffered by those who are misgendered are an accurate reflection of the personal and social significance of gender identity. And here, the definition of gender identity does come into play: a definition of gender identity that makes it difficult to see why gender identity is important, significant, or deserving of respect would seriously undermine this premise. This points towards a first desideratum for a target concept of gender identity:

7. As already mentioned, trans rights movements are not homogenous. In what follows, I have restricted my focus to some basic claims that are very widely made by trans rights organizations. In addition to having found the claims in the materials of the organizations that are cited in each case, I am not aware of any trans rights organizations which dispute any of the claims I discuss.

8. See, e.g., https://transequality.org/; https://srlp.org/; http://www.hrc.org/explore/topic/ transgender; $\quad$ https://www.stonewall.org.uk/our-work/campaigns/come-out-trans-equality; https://www.amnesty.org.uk/issues/lgbti-rights.

9. I am grateful to an anonymous reviewer for pressing me to clarify this point. 
Di. The definition should render plausible the idea that gender identity is important and deserves respect.

Another key demand of trans rights movements is self-definition, the idea that people should have the right to declare what their gender identity is and to have this declaration treated as decisive. In particular, trans rights movements typically advocate for legal frameworks that allow people to change their official gender by means of a straightforward declaration, rather than having to produce evidence to show that they meet some set of criteria for warranting a change in their official gender. ${ }^{10}$ For example, the current UK legislation, the Gender Recognition Act of 2004, requires people seeking to change their official gender to submit 'evidence' to a panel of 'experts' showing that they have received a medical diagnosis of 'gender dysphoria' and have presented as the gender with which they identify for two years. Trans rights campaigners argue that this system imposes unfair costs on applicants (financially, psychologically, and practically), and that it is demeaning and intrusive. They are calling for new legislation to implement a self-declaration model. ${ }^{11}$

This demand can be understood as a call for what Bettcher (2009) has described as a norm of 'First Person Authority' (FPA), a principle stating that a person should be treated as the final and decisive authority on their own gender identity. Accordingly, we can add a second desideratum:

D2. The definition should be compatible with a norm of FPA.

It is worth noting that Bettcher distinguishes between an epistemic norm of FPA and an ethical norm of FPA. An epistemic norm of FPA is justified by the claim that the person who is accorded the FPA has a 'serious epistemic advantage' (Bettcher 2009: 100) concerning the relevant subject matter compared to others, whereas an ethical norm of FPA is justified by the ethical badness of failing to treat the person's avowals as decisive. Bettcher herself defends FPA as an ethical norm. She argues convincingly that a key aspect of transphobic oppression, and one that ties together many different manifestations of transphobia, including physical violence against trans people, is the mistaken belief that trans identities are inauthentic or invalid, and that trans people are either maliciously deceptive or tragically confused (Bettcher 2007; 2009). The ethical imperative for

10. See, e.g., https://transequality.org/; https://srlp.org/; http://www.hrc.org/explore/topic/ transgender; $\quad$ https://www.stonewall.org.uk/our-work/campaigns/come-out-trans-equality; https://www.amnesty.org.uk/issues/lgbti-rights.

11. See https://www.stonewall.org.uk/gender-recognition-act. At the time of writing, a government consultation has just opened on reforming the act. 
adopting a norm of FPA, according to Bettcher, stems from the need to counteract these transphobic dynamics. An ethical norm of FPA can be defended by reference to the considerations Bettcher raises even if there is no reason to think that people are in a strongly privileged epistemic position with regard to their gender identity. I will leave it open what kind of norm of FPA the target concept of gender identity needs to uphold, since I take it that upholding either an ethical or an epistemic norm of FPA would be sufficient for the concept to do the required work. Note that upholding an ethical norm is much easier than upholding an epistemic norm: all that is necessary is that the account does not generate any reasons for rejecting FPA that are weighty enough to outweigh the ethical reasons in favour of it that are identified by Bettcher.

A third key demand of trans rights movements is affordable and nonburdensome access to transition-related healthcare (e.g., hormone therapy and surgeries such as double mastectomy with chest reconstruction or breast augmentation, colloquially termed 'top surgery', and orchiectomy, vaginoplasty, or phalloplasty, colloquially termed 'bottom surgery') (Koyama 2006). ${ }^{12}$ In countries in which healthcare is provided by the state, such as the UK, this takes the form of advocating for transition-related healthcare to be provided by the national provider, whilst in countries in which healthcare is provided under insurance, such as the US, this takes the form of advocating that insurers be required to cover transition-related healthcare under their policies. In both cases, as well as financial accessibility, trans rights advocates call for the removal of unnecessary and lengthy procedural barriers to accessing transition-related healthcare (Serano 2016). A major rationale for this demand is that delay in accessing transition-related healthcare has been shown to have a strong negative effect on the mental health of trans people (Bailey et al. 2014).

Intuitively, it seems as though this demand should feed in to the definition of gender identity. If the target concept of gender identity were completely detached from the need for transition-related healthcare, it would be hard to uphold the seemingly obvious claim that good access to transition-related healthcare is properly understood as a trans rights issue. In other words, if it were seen as a complete coincidence that, for example, a particular individual (a) is a trans person with a male gender identity, and (b) feels a need for top surgery, it would be difficult to explain why his need to access to transition-related healthcare is connected to his social position as a trans person. We therefore need a desideratum that links gender identity with the need for transition-related healthcare.

However, there are grounds for caution here. Some trans people do not wish to change any of their bodily features to reflect their gender identity, and others

12. By 'transition' in the context of this paper I mean to refer to the process of seeking to move from being perceived and treated as a member of one gender category to being perceived and treated as a member of another gender category. 
wish to change some of the bodily features that are commonly associated with gender, but not others. It is therefore important that this desideratum be phrased in a way that avoids the implication that all trans people desire transition-related healthcare. In particular, we cannot require an account of gender identity to be able to justify the claim that (e.g.) a person with a male gender identity who has breasts automatically needs top surgery simply in virtue of his gender identity. Such an account would imply that those trans people who do not wish to change any of their bodily features are mistaken about their gender identity, thereby undermining FPA.

The following wording expresses the requisite caution:

D3. The definition should be compatible with the idea that some trans people have a need for transition-related healthcare that is based on their gender identity. ${ }^{13}$

Having arrived at three desiderata from reflecting on the work that trans rights movements need gender identity to do, I will now propose three more desiderata based on the features that a target concept needs to have in order to do this work well. The first of these relates to the issue that motivates this paper: the circularity exhibited by the folk concept of gender identity. One barrier to the promotion of trans rights is a lack of understanding of trans experiences, including confusion about what it is to be a trans person. For example, a fairly common misconception is that all trans people have had, or plan to have, genital surgery. Clearly, increased understanding of what it is to be trans would aid the promotion of trans rights. Another change that would also help would be greater understanding and uptake of the term 'cis' to describe those whose gender identity corresponds to the gender they were assigned at birth. This would have two benefits. First, it would reduce 'othering' of trans people: compare the importance of having a term, 'heterosexual', to refer to men who exclusively experience attraction to women and woman who exclusively experience attraction to men, rather than simply describing such people as 'normal'. Second, it would

13. This wording might be thought insufficiently demanding: it is often claimed by trans rights advocates that affordable and non-burdensome access to transition-related healthcare is not only a need but a right. Whilst I am extremely sympathetic to this claim, I note that any claim about rights raises general questions about what sort of thing a right is, the contexts within which rights apply, and how the corresponding obligations should be understood, which I cannot settle here. This is my reason for phrasing the desideratum in terms of needs rather than rights. Moreover, the language of need is, by itself, enough to rebut suggestions that a trans person's request for transition related healthcare stems purely from, say, aesthetic preferences, rather than being something that is crucial for their wellbeing. Further work in advocating for a right to transitionrelated healthcare is a separate (though important) project that builds upon the idea of a need for transition-related healthcare. I am grateful to Aness Webster for pressing me on this point. 
facilitate greater attention to the phenomenon of cis privilege, that is, the fact that one's life is likely to be easier in a number of ways, large and small, if one is cis as opposed to trans.

Since the concept of gender identity plays a prominent role in accounts of what it is to be trans or cis, one key function that the concept of gender identity should perform is to help increase understanding of these terms among those not yet familiar with them. Clearly, a circular or unclear concept cannot do this. Having a clear and non-circular definition of gender identity is also necessary if the concept is to be deployed in legal contexts, which is something at which trans rights campaigns regularly aim.

Accordingly the fourth desideratum is:

D4. The definition should be clear and non-circular.

Some caution is needed here. An unfortunate and wide-spread attitude takes the legitimacy of trans identities to be dependent on the recognition of cis people. In other words, many seem to think that in order to be valid, trans identities must be rendered intelligible from a cis perspective. This is of course profoundly at odds with the aim of countering transphobia (Bettcher 2009; Scheman 1997; Stone 2006; Stryker 1994). Let me make it absolutely clear, then, that I take the value of a greater general understanding of gender identity to stem from the likely beneficial effects this would have for movements to advance trans rights, and not from any implication such an understanding might be supposed to have for the legitimacy of trans identities.

A fifth desideratum is needed to reflect the fact that some trans people are non-binary, which is to say they have a gender identity that is not 'man' or 'woman'. Although some people identify as 'non-binary' specifically, the term 'non-binary' can also function as an umbrella term for all identities other than 'man' and 'woman'; this includes identities such as 'agender' (having no gender), 'genderfluid' (moving between genders) and 'genderqueer' (calling into question received notions of gender). In this paper I shall primarily use 'nonbinary' in its umbrella sense. Since some trans people are non-binary, it is clear that an account of gender identity that did not fit well with the identities and experiences of non-binary people could not be effective in securing and improving the rights of all trans people. ${ }^{14}$ Accordingly, we can add a fifth desideratum:

14. It is worth mentioning that although all non-binary people can be considered trans in the sense that they have a gender identity other than the gender that were assigned at birth (given that very nearly all infants are assigned either a male or a female gender at birth), not all non-binary people consider themselves to be trans or find the notion of being trans illuminating or relevant with respect to their own experiences. 
D5. The definition should apply equally well to binary and non-binary identities.

A final desideratum is needed to reflect the fact that transfeminist approaches are, and have long been, a key part of trans rights movements (Bettcher 2007; 2014; Koyama 2006; Serano 2016). Transfeminist approaches are committed to analysing gender-based oppression in a way that understands transphobia and misogyny as intimately related in complex ways, with particular attention to the experiences of those situated at the intersection of these oppressions, that is, trans women. Transfeminists argue that paying attention to the dynamics of transmisogyny - the specific combination of transphobia and misogyny that is directed at trans women-alerts us to various important features of genderbased oppression as a whole, and points towards solutions that are emancipatory for people of all genders, whether trans or cis. An account of gender identity that was incompatible with transfeminist approaches would instigate a significant split within trans rights movements, and would also make it difficult for those movements to work in concert with other feminist movements. This would be highly counterproductive.

In order to be compatible with transfeminist approaches, a definition of gender identity must be friendly to critiques of current gender norms and social structures that go beyond the fact that these norms frequently miscategorize trans people. Accordingly, the final desideratum is:

D6. The definition should combine well with broader critiques of current gender norms and social structures.

Thus, the six desiderata that I will use to assess possible target concepts of gender identity are as follows:

D1: The definition should render plausible the idea that gender identity is important and deserves respect.

D2: The definition should be compatible with a norm of FPA.

$\mathrm{D}_{3}$ : The definition should be compatible with the idea that some trans people have a need for transition-related healthcare that is based on their gender identity.

D4: The definition should be clear and non-circular. 
D5: The definition should apply equally well to binary and non-binary identities.

D6: The definition should combine well with broader critiques of current gender norms and social structures.

\section{Existing Accounts of Gender Identity}

I will now consider the three accounts of gender identity that have been put forward in the analytic philosophy literature and assess how well each of them meets the five desiderata. For reasons of space, I will not consider all six of the desiderata in relation to each account, but will in some cases focus only on the main strengths and weaknesses. It is important to note that there is no reason to think that the authors I survey are themselves committed to all (or even any) of the desiderata I have set out thus far, and that accordingly my discussion tells us nothing about whether these accounts succeed by their own lights.

\subsection{The Dispositional Account}

According to McKitrick (2015), gender identity consists of a disposition or cluster of dispositions to behave in ways that are perceived as gendered in the social context within which the subject is situated..$^{15}$ These dispositions are contrasted with actual behaviour:

Being gendered is not exclusively a matter of how one is actually behaving currently, but also a matter of how one is disposed to behave. These dispositions can be masked, or overpowered by other dispositionsdispositions to bow to social pressure, or pursue incompatible goals. (McKitrick 2015: 2579)

It is important to note that McKitrick remains neutral on the origin of these dispositions (2015: 2580).

Here is McKitrick's definition in full:

$x$ is gender $G$ iff

$\mathrm{x}$ has (sufficiently many, sufficiently strong) dispositions $\mathrm{D}_{1} \ldots$... Dn to behave in ways $B_{1} \ldots$. Bn in situations $S_{1} \ldots$. Sn, and

15. In the main body of the paper, McKitrick refers to 'gender', rather than 'gender identity', but she makes it clear at the outset that she is referring to gender in the sense of 'gender identity' (2015: 2577). 
The relevant social group considers behaving in ways $\mathrm{B}_{1} \ldots \mathrm{Bn}$ in situations $\mathrm{S}_{1} \ldots$... Sn to be G.

The relevant behaviors could include modes of dress, posture and mannerisms, productive and leisure time activities, styles of communication and social interaction. . . Candidates for gender G include 'masculine,' 'feminine,' 'trans,' 'queer,' etc. (2015: 2581) ${ }^{16}$

Importantly, McKitrick conceives of these dispositions as extrinsic, in the sense that they are about a person considered in a particular context and their relationship to that context.

First, the definition's strengths. McKitrick's definition avoids the circularity that threatens the folk concept of gender identity by giving independent content to the gender terms that appear in the definition of gender identity. Recall the folk definition: 'Gender identity is a sense of oneself as a man, woman, or some other gender.' For McKitrick, the content of gender terms that appear in this definition is set by the behaviours that the relevant social group consider to be characteristic of that gender group. According to McKitrick, then, to say that someone has a female gender identity is to say that she has dispositions to behave in ways that people in her social context consider to be feminine, that is, characteristic of women. This tells us what gender identity is without appealing to the concept of gender identity, thus avoiding circularity and meeting $\mathrm{D}_{4}$.

The definition can also meet $\mathrm{D}_{5}$, the requirement to apply equally well to binary and non-binary people. If there are stereotypes about non-binary people in a given social context, then the definition can handle non-binary identities in the same way as it handles binary identities. If there are no such stereotypes - for example, if the context is one where non-binary identities are hardly acknowledged to exist and the only stereotypes concern masculine and feminine ways of behaving - then non-binary identities cannot be treated the same way as binary identities. However, the account can easily be extended to allow for non-binary identities to be defined relative to those identities for which there are stereotypes. For example, one might say that if someone has no dispositions to behave either in ways considered masculine or in ways considered feminine, then they have an agender gender identity. So the dispositional account does well with regard to both $\mathrm{D}_{4}$ and $\mathrm{D}_{5}$.

However, the dispositional account also has some serious weaknesses. ${ }^{17}$ Consider D1, the requirement that the definition render plausible the idea that

16. Note that treating 'trans' as a gender, as McKitrick does here, is controversial; most trans people do not consider their gender to be 'trans' but rather 'man', 'woman', 'genderqueer', etc.

17. Recall that these are weaknesses as a potential target concept for the current ameliorative inquiry; they may not be weaknesses relative to other purposes and commitments. 
gender identity is important and deserves respect. The dispositional account might initially appear to meet this desideratum, because being forced to behave contrary to one's dispositions is a cost-and so it would seem that a person's dispositions relative to gender norms (i.e., their gender identity, according to the dispositional account) are important and deserve respect. However, problems arise when we consider D6 - the need to allow for critical stances towards gender norms - alongside D1. The shared beliefs about typical behaviour for different genders - let us call these 'gender stereotypes' - that serve as a point of reference for the dispositions on which McKitrick focuses are both contingent and regarded by many as highly problematic. Yet if we adopt a critical stance towards these stereotypes, it is difficult to also view our dispositions to behave in ways that align with certain of these stereotypes as either important or deserving of respect.

An example may help. Suppose there is a society which is divided into aristocrats and peasants, and in which different modes of dress, posture and mannerisms, productive and leisure time activities, and so on are associated with these social classes. (Needless to say, this is a very unjust society.) Further suppose that people have dispositions to behave in these kinds of ways. It is hard to see why any significance or respect should be attached to these dispositions. Certainly, someone who claimed that it was important for them to continue to be treated as an aristocrat (e.g., addressed with the typical forms of address for addressing an aristocrat) due to their aristocratic dispositions would not have a compelling claim to be so treated. If we adopt a critical stance towards gender norms, then the disposition account places gender identity on a structurally similar footing as aristocratic or peasant identity in this scenario. Therefore, the dispositional account can either show that gender identity is important and deserves respect, or allow for critical stances towards gender norms; it cannot do both. There is thus at least one desideratum that the account cannot meet.

\subsection{The Self-Identification Account}

A recent proposal from Bettcher (2017) marks a distinct and novel approach to conceptualizing gender identity. She introduces it as follows:

The cleanest move may well be to avoid [the issues raised by other accounts of gender identity] altogether through an appeal to sincere selfidentification. Admittedly, this means trans women who don't yet selfidentify as women aren't yet women (in this sense). That said, once she does self-identify as a woman, she may well re-assess her entire life by 
saying she's always been a woman (something we should respect too). (Bettcher 2017: 396) ${ }^{18}$

Based on Bettcher's other work (2009), I understand 'self-identification' here to mean claiming, or being disposed to claim in relevant circumstances, that one is a person of a certain gender. On this account, to have a female gender identity is to be someone who is disposed to reply to the question, 'What is your gender?', with the statement, 'I am a woman' (or words to that effect) and to be acting in good faith in doing so. Here, then, self-identification refers to the act of expressing or claiming a certain identity, or, at least, being disposed to make such expressions or claims.

The self-identification account is a rather deflationary way of thinking about gender identity. In common parlance, gender identity is usually thought of as the property of a person that makes them inclined to engage in certain acts of self-identification and that is expressed when they do engage in acts of selfidentification. The dispositional account, for example, aligns with this idea. By contrast, the self-identification account equates gender identity with sincere selfidentification. This move distances the account from the idea that there is any reasonably unified property that can be thought to underlie different acts of selfidentification.

A major strength of the self-identification account is that it meets D2, the need to be compatible with a norm of FPA. As we saw in Section 2, Bettcher supports an ethical norm of FPA rather than an epistemic norm. The selfidentification account is clearly compatible with ethical FPA: nothing in the account weighs against a practice of treating people's declarations of their own gender as authoritative - quite the reverse. Moreover, the account can even support the more demanding epistemic norm of FPA, since it renders it impossible for a person to be mistaken about their own gender identity at a given moment in time. The account thus offers a very pronounced form of privileged epistemic access, at least synchronically. The account also unequivocally meets $D_{5}$, the requirement to be equally applicable to non-binary identities, and it is clearly compatible with D6, the need to allow for critical stances towards gender norms: since the account makes no reference to gender norms, it presents no barrier to critiquing those norms.

Nevertheless, the self-identification account also has some significant weaknesses. Most importantly, it fares very poorly at showing that gender identity is

18. Bettcher's wording in presenting the account is slightly equivocal: although it is clear that she recommends the account as a solution to certain difficulties with other accounts, it is not quite clear whether she fully endorses it. 
important and deserves respect (Di). As we have seen, on this account gender identity is equated with a disposition to make certain kinds of assertions. This means that the account makes gender identity seem trivial: why should we care about dispositions to utter certain sentences? Insofar as we care about gender identity we seem intuitively care about it as whatever it is that makes people want to utter those sentences, or whatever it is that they express when they do utter them. It is not simply that the self-identification account needs to say more in order to explain how gender identity is important and deserves respect, but rather that it is difficult to see how the account can ever say more on this, due to its minimalist stance.

The self-identification account also struggles with $\mathrm{D}_{3}$, compatibility with possible need for transition-related healthcare: it is difficult to perceive any relationship at all between a linguistic disposition and the sort of felt need for one's body to be different that would prompt the desire to access transitionrelated healthcare. Again, it is hard to imagine what might be added to the selfidentification account to enable it to meet this desideratum. ${ }^{19}$ There are, then, two desiderata which the self-identification account seems unable to meet.

\subsection{The Norm-Relevancy Account}

In previous work (Jenkins 2016), I have offered an account of gender identity that, like the dispositional account, appeals to social norms about how members of various genders ought to be, and uses those norms to give content to gender terms as they appear in the definition of gender identity. In contrast to McKitrick, however, my account focuses on a relationship to these norms that is much looser than a disposition to comply with them, namely, the fact that someone experiences those norms as relevant to them. On my account, which I will describe as the 'norm-relevancy account', to say that someone has a female gender identity is to say that she experiences the norms that are associated with women in her social context as relevant to her.

The account begins with a picture of the way that agents interact with the norms governing social space. This picture is explained by way of a metaphor borrowed from William E. Cross via Haslanger (2012a), that of an embodied 'map' of social space that is calibrated relative to one or another set of social norms. The idea conveyed by this metaphor is that a person typically has an

19. It might seem that the self-definition account also struggles with $\mathrm{D}_{4}$ (non-circularity). However, the account (as I have interpreted it) is not circular. It does not explain self-identification by referring back to gender identity; rather, it declines to explain it at all. Gender identity is simply equated with disposition to sincerely utter sentences such as 'I am a non-binary person', such that no stipulation is made about what a person intends to convey by making such utterances. It would be a mistake to take the account's minimalism for circularity. 
internalised sense of the norms operating in social spaces that they regularly navigate, and the implications of those norms for the status of their own behaviour as norm-compliant or norm-violating, where this sense can be thought of by analogy with annotations made on a personal copy of a standard-issue map of the physical region.

To take a very basic example, suppose that a woman, a man, and a nonbinary person all work in the same building, and each is given a map of that building and asked to annotate it in ways that indicate how they experience different spaces. The woman's map might have the female toilets marked as a space where she is able to go and the male toilets marked a space where she is not able to go; the man's map might be the opposite way around; and (assuming, as is sadly common, that the building lacks gender-neutral toilets) the non-binary person's map might have all toilets marked as uncomfortable places fraught with stress and danger. This example concerns explicitly gendered spaces, but we can extend it to apply to spaces that are not explicitly gendered. Suppose that the workplace is a hostile environment for women-specifically, in meetings, women are regularly talked over, ignored, or belittled. In this case, the meeting room might be marked as 'somewhere I am not supposed to speak much' on a woman's map, but not on a man's map. Or think of the way that a woman might experience certain streets as 'no-go' areas during certain times of day, whereas a man might feel fine walking in those streets regardless of the time of day.

The map is tacit in the sense that people are not always explicitly aware of the way they experience social spaces, and it is embodied in the sense that responses to interactions with norms can produce bodily responses. For example, entering a space that is designated on your 'map' as a 'no-go' area for people like you might result in feelings of bodily awkwardness, tension, and even the physiological responses associated with fear.

Importantly, a person's gender 'map' need not correspond to the way one is seen by others; a person might know that other people judge their behaviour by reference to norms of (say) masculinity, but their own sense of whether their behaviour is norm-compliant or norm-violating may take norms of femininity as a reference point. Again, this need not be something they are consciously aware of. An example of the kind of 'sense' I have in mind can be found in Julia Serano's description of her experience as a child who had been assigned male at birth (she later came to identify as a woman):

I had an unexplainable feeling that I was doing something wrong every time I walked into the boys' restroom at school; and whenever our class split into groups of boys and girls, I always had a sneaking suspicion that 
at any moment someone might tap me on the shoulder and say, "Hey, what are you doing here? You're not a boy." (Serano 2016: 78) ${ }^{20}$

Clearly, any given person's 'map' will be highly intersectional, since social spaces are governed by norms about many aspects of social identity other than gender, and these norms interact with, and indeed co-construct, one another in complex ways. For example, a black woman might experience the meeting room as hostile in different and more pronounced ways compared to how a white woman experiences it.

These ideas are expressed in the formal definition I offer of the concept of gender identity:

S has a gender identity of X iff S's internal 'map' is formed to guide someone classed as a member of $X$ gender through the social or material realities that are, in that context, characteristic of Xs as a class. (Jenkins 2016: 410)

This definition makes reference to a notion of gender 'classes'; by this I mean, following Haslanger (2012a), social roles that are both (a) coercively imposed on the basis of perceived relationship to possibilities of biological reproduction, and (b) hierarchical in nature such that members of the masculine category are privileged and members of the feminine category are subordinated.

The overall picture that emerges from the norm-relevancy account is as follows: there are social practices that position people as members of certain hierarchical gender classes. Each of these gender classes is the locus of a complex set of norms about how occupants of that class ought to be and ought to behave. In contemporary Western society, these norms include norms about personality, occupation, hobbies, modes of interaction, and modes of self-presentation. They also include norms about bodies-for instance, the norm that men should have penises and should not have breasts, and the norm that women should have vulvas and should not have beards. Against this backdrop, people have an inner sense of their own 'locatedness' with regard to these norms, which might diverge from the way they are in fact positioned. When they experience their own behaviour as norm-compliant or norm-violating, one or another set of these norms is functioning as the benchmark for (non-)compliance.

Crucially, I understand 'experiencing a norm to be relevant to oneself' to be perfectly compatible with behaving in contravention of that norm and with disapproving of that norm. To illustrate what it might be for someone to experi-

20. Serano herself would not describe this sense as gender identity, because she reserves the term for 'the way [one] consciously relate[s] to [one's] own gender'. Instead, she describes it as one consequence of what she terms 'subconscious sex' (Serano 2016: 81-83). 
ence a norm as relevant to them whilst disapproving of it and not complying with it, I offer the case of a woman who does not remove body hair from her legs (2016: 411-412). Such a woman may well experience an awareness of the normviolating nature of this aspect of her bodily presentation even if she is happy with her choice not to remove her leg-hair, and even if she has a strongly critical attitude towards the relevant norms. For example, she might feel conscious of her hairy legs when she wears clothing that reveals them in a way that she would not feel conscious if she had hairless legs, even if this consciousness is something she experiences positively, as an enjoyable sense of transgression or rebellion. This awareness of the norm-violating nature of her leg-hair, I contend, is something the woman can only have in dependence on experiencing her behaviour in relation to the norms associated with women, since only those norms direct that legs should be hairless. ${ }^{21}$

A defender of the norm-relevancy account need not be committed to the claim that gender norms are uniform across social space. The social expectations placed on women, for example, vary between different communities, and are heavily inflected by interlocking norms about race, class, sexuality, and so on. Thus, it would be vanishingly unlikely that a person would take all of the norms associated with women to be relevant to her. Moreover, that type of comprehensive relevancy relationship is not required. As I intend the norm-relevancy account, for a person to have (say) a female gender identity, she simply needs to take some significant subset of the norms associated with women be relevant to her, and not to take a greater subset of the norms associated with another gender role to be relevant to her. ${ }^{22}$

Because I will argue that the norm-relevancy account meets all six of the desiderata, in some cases with minor additions, I will consider each desideratum in turn rather than focusing on strengths and weaknesses.

\section{Dı: The definition should render plausible the idea that gender identity is important and deserves respect.}

In order to see how the norm-relevancy account makes sense of the idea that gender identity is important and deserves respect, we need to consider what

21. Note that the norm-relevancy account differs from the dispositional account in that it does not tie gender identity to a disposition to behave in ways that are regarded as masculine or feminine: one can experience a norm as relevant to oneself without having a disposition to behave in the way that the norm demands.

22. I lack the space to explore in any detail the issue of exactly how large this subset needs to be. It seems likely that the relevant requirement would need to involve both the size of the subset relative to the norms of femininity operating in that context, and the size of the subset relative to the size of other subsets of gender norms the person also experiences as relevant. I am grateful to an anonymous reviewer for raising this point. 
Alissa Bierria has termed 'the social dialectic of agency' (2014: 131). Bierria observes that although it seems natural to many to locate agency solely within the agent herself, in fact our understanding of agency in a social context should extend to the reception of the action by observers. In general, an agent not only acts intentionally, she also acts on the presumption that her act will communicate to observers at least roughly what she meant it to, including at least a partially accurate sense of her intentions in so acting. In this sense, the acts we end up performing are co-constructed by ourselves and by others around us who perceive those acts. As Bierria puts it, 'even if an agent develops her intentions and acts accordingly, others who observe the agent's action also construct narratives of meaning about her actions, empowering them as social authors of her autonomous action' (2014: 131).

According to the norm-relevancy account, to have a certain gender identity ('woman', for example) is to experience one's actions as norm-compliant or normviolating with respect to the norms for that gender, rather than the norms for any other gender. For example, a person with a female gender identity in a European or American society would tend to experience wearing a dress as norm-compliant behaviour, rather than as norm-violating behaviour. Now suppose that such a person is perceived by others as a man-in other words, her gender identity is not respected-and that she wears a smart dress to a relatively formal occasion, such as a university graduation. Her intention, let us suppose, is to dress in an aesthetically pleasing but not particularly remarkable way that is sensitive to the formality of the occasion. Those observing her, however, interpret her as dressing in an extremely conspicuous and deliberately challenging way that undermines the formality of the occasion. This is because whilst wearing a smart dress to an occasion of this sort is norm-compliant relative to the norms of femininity, it is highly transgressive relative to the norms of masculinity. Thus, there is a marked disconnect between the intended and the perceived meaning of this agent's action. Continuously experiencing this sort of disconnect amounts to a serious form of social disempowerment. To employ terminology that Bierria borrows from María Lugones (2003), it constitutes 'disenfranchisement', a deprivation of the authority to prompt social recognition of one's intentions (Bierria 2014: 132).

The norm-relevancy account of gender identity shows that gender identity is important and deserves respect because disrespect for a person's gender identity leads to disenfranchisement of the kind identified by Lugones and Bierria.

D2: The definition should be compatible with a norm of FPA.

Compatibility with an ethical norm of FPA requires only that an account does not offer any reasons against FPA that would outweigh the ethical considerations in favour of it. The norm-relevancy account meets this standard. 
Previously (Jenkins 2016), I took the norm-relevancy account to be compatible with an epistemic norm of FPA. I claimed that it entails that everyone in fact has the gender identity that they take themselves to have-a strong form of epistemic privilege that would justify an epistemic norm of FPA. However, Bettcher (2017) has pointed out that the account does not yield the expected results about the gender identities of some trans people. Bettcher gives the example of a trans woman who has just begun to present herself outwardly as a woman. She asserts that such a woman might potentially turn out to have a gender 'map' that is organised around the norms that are applied to men in her social context-presumably, because these are the norms that have been applied to her by others all her life until now. ${ }^{23}$ Thus, it seems that some people might have a gender 'map' that is not aligned with the norms of the gender with which they consciously identify. In light of this, and contrary to my previous claims, it is clear that the norm-relevancy account does not entail that everyone is always right about their own gender identity, and therefore does not secure the strong epistemic privilege needed to support an epistemic norm of FPA. However, the norm-relevancy account still meets the less-demanding standard of compatibility with ethical FPA, and therefore satisfies D2. ${ }^{24}$

$\mathrm{D}_{3}$ : The definition should be compatible with the idea that some trans people have a need for transition-related healthcare that is based on their gender identity.

Currently, gender norms include norms about how bodies should be. For example, 'men should not have breasts' is a gender norm currently in operation in mainstream contexts in Western society. These norms provide a link between gender identity and those properties of the body usually considered to be sex characteristics. A person who identifies as a man may well experience the norm 'men should not have breasts' as relevant to him. ${ }^{25}$ It is natural to think that feeling that one's body transgresses a norm that one experiences as relevant to oneself may be distressing to some people. This allows us to make sense of the idea

23. A similar point is made by Matthew Salett Andler (2017) although Andler's expression of the point rests on a misunderstanding of my view; see Section 4.1 below.

24. Establishing that the norm-relevancy account entailed that everyone has the gender identity that they think they have was important for the purposes of that paper because I was seeking to solve the 'inclusion problem', the challenge of finding an appropriately inclusive concept of 'woman' for use in feminist practice. Since that time, Mari Mikkola has argued, in my view convincingly, that the inclusion problem rests on a confusion and can therefore be deflated rather than solved (2016: Chapter 5).

25. Although he need not do so; a person does not have to experience all the norms associated with masculinity as relevant to himself in order to have a male gender identity. 
that (e.g.) if a person with a male gender identity feels the need for top surgery, this is related to his gender identity.

Note that the dispositional account does not justify the claim that a person with a male gender identity who has breasts necessarily needs top surgery simply in virtue of his gender identity. For one thing, it is possible to experience a norm as relevant to oneself without wishing to comply with it. For another, there is no general principle that people should be helped to bring their bodies into line with all of the norms they experience as relevant-and indeed, many people would (rightly, in my view) be extremely wary of such a principle, particularly with reference to disabled embodiment but perhaps also with reference to beauty norms. This is in line with how $\mathrm{D}_{3}$ is stated (see Section 2 above), so the normrelevancy account meets this desideratum.

D4: The definition should be clear and non-circular.

The norm-relevancy account of gender identity spells out the folk concept in more detail: it equates 'having a sense of oneself' as a particular gender with experiencing the norms associated with that gender in one's cultural context as relevant to one. It avoids circularity because these norms are not defined in terms of gender identity but in terms of gender classes, which are understood to be based on social practices, structures, and arrangements. Thus, the account is clear and non-circular.

D5: The definition should apply equally well to binary and non-binary identities.

I take it that there are, in many if not most contexts, currently no gender classes, and indeed no imposed social roles at all (hierarchical or otherwise), that are associated with non-binary identities. It may be difficult to see, then, how the norm-relevancy account can accommodate non-binary gender identities: in many contexts, the relevant gender classes are simply not out there in the world, available for the definitions to refer to, in the way that the classes 'man' and 'woman' are available. However, this does not mean that the norm-relevancy account is unable to accommodate non-binary identities, because the strategy of referring to gender classes to define gender identity does not have to depend on a straightforward 1:1 correspondence between the identity and some particular gender class. Rather, it just needs to be a way of locating the identity with reference to some existing gender class or classes.

In my previous work, I was only able to address this point in passing. I suggested that in contexts where there are no non-binary gender classes, non-binary gender identities can be identified by contrast to the classes of 'man' and 'wom- 
an' (Jenkins 2016: 410, Footnote 40). (In contexts where there are non-binary social roles, the solution is of course more straightforward.) Clearly, however, this needs spelling out in more detail for the present purposes. In order to do this, I will add a second metaphor to the norm-relevancy account besides the one of 'maps' discussed above.

Imagine that injunctions about how people of different genders are supposed to behave are broadcast on different radio frequencies, and each person has a radio that can be tuned in to different frequencies. Suppose there are just two channels: the 'woman' channel, and the 'man' channel. A person's radio can be tuned in to the 'woman' channel, or it can be tuned to the 'man' channel, but these are not the only two possibilities. The radio could switch back and forth between the channels, or it could be a special radio capable of playing two channels simultaneously, or it could be tuned to a frequency between the two so that both channels come through in unusual and mingled ways, or it could be tuned to no channel at all. ${ }^{26}$ This provides a model for thinking about how even if there are (in a certain social context) only imposed social roles for two genders, a person can still have a non-binary gender identity in the sense defined by the norm-relevancy account. ${ }^{27}$

Here is a definition of non-binary gender identities, conceived of as an umbrella term referring to all gender identities other than 'man' and 'woman':

A subject $S$ has a non-binary gender identity iff $S$ 's internal 'map' is neither formed so as to guide someone classed as a woman through the social or material realities that are, in that context, characteristic of women as a class, nor formed to guide someone classed as a man through the social or material realities that are, in that context, characteristic of men as a class.

More precise definitions of particular non-binary gender identities can be given as follows:

$S$ has a genderfluid gender identity iff $S$ 's internal 'map' is at times formed so as to guide someone classed as a woman through the social or material realities that are, in that context, characteristic of women as a class, and at other times formed to guide someone classed as a man

26. These possibilities are intended to express, respectively, genderfluid identity, bigender identity, genderqueer identity, and agender identity.

27. A further benefit of the radio metaphor is that it conveys the difference between experiencing a norm as relevant to oneself and following a norm more clearly than the map metaphor does: one can be tuned in to the woman channel without actually obeying any of the injunctions that are broadcast on it. 
through the social or material realities that are, in that context, characteristic of men as a class.

$S$ has an agender gender identity [or: S lacks a gender identity] iff S does not have an internal 'map' that functions to guide them through the social or material realities that are, in that context, characteristic of any gender class.

I cannot here give a full explanation of the many non-binary gender identity terms that are in use, but the three definitions offered here should suffice to show that the norm-relevancy account does not have a general difficulty in including non-binary gender identities. ${ }^{28}$

D6: The definition should combine well with broader critiques of current gender norms and social structures.

The norm-relevancy account very clearly meets this desideratum, because it actually incorporates such critiques via the notion of gender classes.

\section{Defending the Norm-Relevancy Account}

The previous section shows that the norm-relevancy account satisfies all six of the desiderata, in one case (D5) with a slight extension, whilst both the dispositional account and the self-identification account are unable to meet one or more of the desiderata. Clearly the norm-relevancy account is the best candidate for the target concept of gender identity (within the present ameliorative inquiry) out of the three existing accounts. In order to establish just how strong a candidate the norm-relevancy is, however, it is necessary to check that it does not suffer from other defects that have not yet been highlighted through considering the desiderata. Accordingly, before concluding, I will consider and respond to three criticisms of the norm-relevancy account.

\subsection{Cisnormativity}

Andler (2017) argues that the norm-relevancy account is 'cisnormative' because it requires us to 'problematically [conceptualize] all gender identity through a

28. Exactly how these definitions are interpreted will depend on how the cut-off points are defined for male, non-binary and female gender identities in terms of how many norms a person experiences as relevant, and issue that I lack space to address here (see Footnote 22 above). I anticipate that a full response to this point might include some fuzzy boundaries. 
cisgender frame'. This charge is partly based on a misconception about how the norm-relevancy account would respond to cases of trans people who have embodiments that are non-normative for their identified gender but who experience this as unproblematic-for example, a trans woman who experiences her penis straightforwardly as a womanly body part. Andler contends that the norm-relevancy account cannot categorise such people as members of the gender they consider themselves to be. In fact, the norm-relevancy account can yield the expected result in such cases because, as explained above, it does not require a person to be 'tuned in' to all of the norms associated with the relevant gender. The trans woman who experiences her penis as a womanly body part is not experiencing the norm 'women should not have penises' as relevant to her. On the norm-relevancy account, if she does experience other norms of femininity as relevant to her, then she has a female gender identity. However, setting this confusion aside, the charge of cisnormativity can also be seen as a response to the fact that the norm-relevancy account defines gender identity by reference to gender classes, which are currently highly cissexist in character, which is to say that they privilege the experiences of cis people whilst undermining the experiences of trans people, and thus systematically function to the detriment of trans people.

It is important to pause here and ask, what exactly is meant by 'cisnormative'? Andler certainly understands this to be negative property, even (given the overall thrust of the article) a fatal defect in a definition of gender identity considered as a proposed target concept. It seems, then, that we should understand 'cisnormative' to apply to accounts that inappropriately centre cis experience, for example by endorsing cissexist standards. On this interpretation, however, the norm-relevancy account is not cisnormative, for although it treats current gender classes as a point of reference, and although these roles are cissexist, it does not endorse these standards. On the other hand, if any centring of cis experiences suffices for an account to be cisnormative, whether appropriate or inappropriate, then the norm-relevancy account's use of current gender roles does render it cisnormative, but it is not clear why this should be considered a problem: since these classes are the ones that currently exist and we must all contend with them, at least for now, taking them as a point of reference seems appropriate. Indeed, it is not clear to me what a substantive account of gender identity could successfully use as a reference point other than some feature of our gendered social structure, such as gender classes or (as in the case of the dispositional account) gender stereotypes - all of which are at present cissexist. In what sense would an account be an account of gender identity if it was not linked to the material reality of gender as a feature of social structures? If this is right, then for as long as our gendered social structure is cissexist, accounts of gender identity will involve 'centring cis experiences' in the very thin sense of taking these cissexist social structures as a reference point. Of course, if gender classes changed so as to be- 
come less cissexist, as they may do in the future, accounts of gender identity, too, would become less cis-centred.

There is, then, an equivocation in the term 'cisnormative' as employed by Andler. On one way of resolving this equivocation it turns out that the term does constitute a genuine defect but is not applicable to the norm-relevancy account; on the other, the term is applicable to the norm-relevancy account (and, I suspect, to any other substantive and non-circular account of gender identity) but does not constitute a genuine defect.

\subsection{Epistemic vs. Ethical FPA}

A second criticism of the norm-relevancy account is made by Bettcher (2017). As explained in the previous section in relation to the norm-relevancy account's ability to meet D2, Bettcher points out that the norm-relevancy account does not give the expected results about gender identity in the case of some trans people. I return to this here because the context in which this observation is made indicates that Bettcher considers this fact to be grounds for rejecting the normrelevancy account considered as a proposed target concept. One way to read this worry is to interpret it as an objection not to the norm-relevancy account as an account of gender identity, but to the norm-relevancy account as a solution to the 'inclusion problem', that is, the question of how to define the 'subject' of feminism, which is how I previously presented it (Jenkins 2016). ${ }^{29}$ In this case, the worry is not relevant to the ameliorative project I am concerned with here, which does not aim to address the inclusion problem. $3^{30}$

There is, however, another interpretation of Bettcher's worry on which it is relevant to my present purposes, which is to interpret her as claiming that a target concept of gender identity ought to have an extension that perfectly matches people's descriptions of their own (current) gender identities. This amounts to proposing that $\mathrm{D} 2$ be altered so that as to require compatibility not merely with ethical FPA, but with the more demanding epistemic FPA. Since epistemic FPA requires that no-one can be wrong about their own gender identity, the normrelevancy account would not be able to meet such a revised desideratum.

The upshot of this is that Bettcher's objection to the norm-relevancy account, if it is a challenge at all in the context of the present ameliorative inquiry, is a challenge to the desiderata I have set out, rather than to the norm-relevancy account's ability to meet those desiderata. Since Bettcher touches on this issue only briefly, it is somewhat difficult to assess this challenge. There are, as far as I can see, no reasons to prefer epistemic FPA to ethical FPA, and indeed Bettcher

29. See Footnote 24 above.

30. For a critique of the inclusion problem, see Mikkola (2016). 
herself, in her 2009 paper, explicitly argues in favour of ethical FPA and against epistemic FPA. It is not fully clear why she then appears to favour epistemic FPA in her 2017 paper; one possibility is that she is simply responding to my mistaken claim that the norm-relevancy account entails that everyone has the gender identity that they think they have, by showing what an account that really did have this consequence would need to look like.

Furthermore, a shift to a version of D2 that required epistemic FPA and could not be satisfied by ethical FPA alone would, I think, raise some problems. To see why this is so, let us look again at Bettcher's self-identification account, which is the only account out of the three considered here which is compatible with epistemic FPA (more precisely, it is compatible with synchronic epistemic FPA). As we saw, the self-identification account is unable to meet $\mathrm{D} 1$, the requirement to show that gender identity is important and deserves respect. These two things are linked: the self-identification account is only able to support (synchronic) epistemic FPA in virtue of placing extremely minimal requirements on having a certain gender identity - and it is that very same minimalism that leaves the account without resources when it comes to showing why gender identity is significant. It seems to me that this tension would arise for different accounts, such that any account that is sufficiently minimal to secure epistemic FPA would be insufficiently substantive to meet $\mathrm{D}_{1}$, and vice versa. If this is right, then moving to a version of $\mathrm{D} 2$ that required compatibility with epistemic FPA would mean abandoning Di. Given the importance of Di to the aims of trans rights movements, this seems highly undesirable.

Certainly, an account of gender identity that entailed that everyone has the gender identity that they think they have whilst also meeting all of the desiderata (including D1) would be preferable to the norm-relevancy account. But given that no such account has been offered so far, and given, too, that there seems to be cause for pessimism about the prospect for developing one, I continue to think that the norm-relevancy account is a good candidate for the target concept of gender identity.

\subsection{Gender Classes and Desiring Subordination}

Unlike the first two objections, the third and final objection that I will consider has not, to my knowledge, been made in print. ${ }^{11}$ The objection concerns the role of gender classes - understood as coercively imposed and hierarchical in nature-in the norm-relevancy account. It goes as follows: According to the norm-relevancy account, trans women are people who have been classed as men

31. It has been raised to me in conversation by Stephanie Kapusta, among others, and I am grateful to an anonymous reviewer for encouraging me to address it here. 
whilst having a female gender identity, and who often seek to change their social position so that they are classed as women. Given the account's reliance on an analysis of gender classes as intrinsically hierarchical, this means that many trans women actively seek to become members of a subordinated social group. This seems to imply either that those trans women must be confused about the nature of gender, or that they must desire their own subordination; both implications are unpalatable.

There are two ways to respond to this objection, depending on whether one agrees with the analysis of gender classes, that is, the claim that gendered social roles are intrinsically hierarchical in nature. Assessing the analysis of gender classes is beyond the scope of this article. Accordingly, I shall show that the norm-relevancy account can be defended from the objection whatever stance one takes on gender classes.

Someone who rejects the analysis of gender classes can simply modify the account to detach it from that analysis, and 'plug in' a different, non-hierarchical account of gendered social roles. This would involve simply changing all references to 'gender classes' to 'gendered social roles', and offering an account of the nature of these roles. This is a very straightforward modification and completely defuses the objection.

If, on the other hand, one does agree with the analysis of gender classes that Haslanger and I endorse, then the situation is slightly more complex. What is required is a way of responding to the apparent dilemma of having to say either that trans women who seek to transition are confused, or that they desire their own subordination. First, let's get clearer on the nature of the dilemma. One thing that is worth noting is that the majority of people don't understand gender classes as hierarchical, which means that trans women are not singled out as especially confused relative to other groups. The real problem with the first horn of the dilemma is not the implication that trans women are confused as such, but rather the more specific implication that trans women would not desire to transition if they understood the nature of gender classes accurately. This is indeed a problematic claim relative to the present ameliorative inquiry, in the sense that it would seriously undermine the aims of trans rights movements. So the unpalatable implications are, on the one hand, that trans women only seek to transition because they are confused, and on the other, that trans women who seek to transition desire their own subordination.

What is needed, then, is a way of showing that a trans woman could accurately understand the hierarchical nature of gendered social roles, not desire to be subordinated, and still desire to transition. One obvious option is to say that what such a trans woman may desire is congruence between the norms she experiences as relevant and the norms others apply to her. Given the explana- 
tion of the significance of such congruence for social agency, this seems like a very reasonable and intelligible desire. ${ }^{32} \mathrm{~A}$ trans woman in this position would most likely view becoming a member of a subordinated social group as a cost of transition, an unwelcome side effect of the thing that she actually desires, meaning that she would not in fact be desiring her own subordination. The appeal of this solution is further strengthened by the fact that in a society that rigidly polices gender norms, a trans woman may well be subordinated in virtue of not conforming to masculine gender norms even before she transitions. If this is so, transitioning would be a matter of exchanging one form of subordination for another, where the exchange also brings significant benefits in terms of congruence between perceived gender and gender identity. It's hard to see how this could be deemed irrational.

What about cases where a trans women not only desires this type of congruence, but actually desires to comply with norms of femininity without being seen as transgressing gender norms? For example, a trans woman may wish to be able to dress in a way that is considered feminine without being targeted for harassment. (Again, it is worth noting that this desire is one that is shared by many cis women, so trans women are not being singled out as desiring something unusual.) A critic of the norm-relevancy account might contend that in these cases, the account does entail that the trans woman desires her own subordination. Now, the relationship between particular gender norms and gender classes as such is a complex one; but in the interests of strengthening the critic's position as much as possible, let us grant that all norms of femininity are implicated in subordination insofar as they function as markers of subordinate status. Is desiring to do things that are markers of subordinate status the same as desiring that one be subordinated? I think not. One can desire the markers for their own sake without desiring to have the status that they serve to indicate. Here, again, we are able to say that the trans woman does not desire her own subordination, but merely desires something which, unfortunately for her, brings subordination along with it.

The norm-relevancy account does not, therefore, entail that trans women only seek to transition because they are confused, nor that trans women who seek to transition desire their own subordination. It allows for trans women to have a full and accurate understanding of the nature of gender classes and gender norms, to desire not to be subordinated, and still to make a rational choice to transition.

32. See Section 3.3 above. 


\section{Concluding Remarks: A Framework for Further Investigation}

I have assessed the three analytic accounts of gender identity developed to datethe dispositional, self-identification, and norm-relevancy accounts-in light of the desiderata I developed for the ameliorative project, and I have argued that, of these three accounts, the norm-relevancy account (slightly extended to better accommodate non-binary identities) is the best candidate for the target concept. Moreover, I have defended the norm-relevancy account from three objections. This suggests that the account is not only the best candidate out of the three considered, but a strong candidate more generally.

It is seldom wise in writing a philosophy paper to aim to deliver the last word on some question, but in this case in particular such an ambition would be especially ill-advised. The topic is one which analytic philosophers have only recently begun to discuss, and which is of tremendous ethical and political significance. Caution is therefore appropriate. There may be considerations I have not taken into account that affect how we should conceive of the desiderata, and entirely new accounts may be developed that are preferable to the norm-relevancy account in various ways. I therefore provisionally and cautiously recommend the norm-relevancy account as the target concept of gender identity that is needed by trans rights movements.

The main contribution I hope to have made in this paper is not so much to advocate for a particular target concept as to clear the ground for better and clearer discussions of gender identity in the future by providing a framework for further investigation. Those who disagree that the norm-relevancy definition captures the target concept of gender identity for an ameliorative inquiry based on the aims of trans rights movements must either (a) disagree with me about what the desiderata for that ameliorative inquiry ought to be, (b) disagree with me about how one or more of the accounts I have considered fares relative to these desiderata, or (c) have a novel account to offer that fares better than the normrelevancy account (or, of course, be doing some combination of these things). It is also the case that other concepts of gender identity may be proposed as part of different projects of conceptual analysis, descriptive or prescriptive/ameliorative. I gladly anticipate that lively disagreement concerning gender identity will continue, and I hope that the framework I have developed helps to clarify the nature of these discussions and so render them as productive as possible.

\section{Acknowledgements}

This paper benefitted from helpful discussions with the following people: Robin Dembroff, Boo Jackson, Stephanie Kapusta, Ian Kidd, Joseph Kisolo-Ssonko, Jen- 
nifer Saul, and Aness Webster. It also benefitted from feedback from audiences at the University of Barcelona, the University of Birmingham, and the Humboldt University of Berlin. I thank all those concerned. In addition, I am grateful to the two anonymous referees for this journal for their constructive comments.

\section{References}

Andler, Matthew S. (2017). Gender Identity and Exclusion: A Reply to Jenkins. Ethics, 127(4), 883-895. https://doi.org/10.1086/691583

Bailey, Louis, Sonja J. Ellis, and Jay McNeil (2014). Suicide Risk in the UK Trans Population and the Role of Gender Transition in Decreasing Suicidal Ideation and Suicide Attempt. Mental Health Review Journal, 19(4), 209-220. https://doi.org/10.1108/MHRJ05-2014-0015

Bettcher, Talia M. (2007). Evil Deceivers and Make-Believers: On Transphobic Violence and the Politics of Illusion. Hypatia, 22(3), 43-65. https://doi.org/10.1111/j.1527-2001.2007. tb01090.x

Bettcher, Talia M. (2009). Trans Identities and First-Person Authority. In Laurie Shrage (Ed.), You've Changed: Sex Reassignment and Personal Identity (98-120). Oxford University Press.

Bettcher, Talia M. (2014). Trapped in the Wrong Theory: Rethinking Trans Oppression and Resistance. Signs, 39(2), 383-406. https://doi.org/10.1086/673088

Bettcher, Talia M. (2017). Through the Looking Glass: Trans Theory Meets Feminist Philosophy. In Ann Garry, Serene Khader, and Alison Stone (Eds.), The Routledge Companion to Feminist Philosophy (393-404). Routledge.

Bierria, Alissa (2014). Missing In Action: Violence, Power, and Discerning Agency. Hypatia, 29(1), 129-145. https://doi.org/10.1111/hypa.12074

Burgess, Alexis, and David Plunkett (2013). Conceptual Ethics I. Philosophy Compass, 8(12), 1091-1101. https://doi.org/10.1111/phc3.12086

Green, Jamison (2004). Becoming a Visible Man. Vanderbilt University Press.

Haslanger, Sally (2012a). Gender and Race: (What) Are They? (What) Do We Want Them to Be? In Sally Haslanger (Ed.), Resisting Reality: Social Construction and Social Critique (221-247). Oxford University Press.

Haslanger, Sally (2012b). Social Construction: Myth and Reality. In Sally Haslanger (Ed.), Resisting Reality: Social Construction and Social Critique (183-218). Oxford University Press.

Haslanger, Sally (2012c). What Are We Talking About? The Semantics and Politics of Social Kinds. In Sally Haslanger (Ed.), Resisting Reality: Social Construction and Social Critique (365-380). Oxford University Press.

Jeffreys, Sheila (2014). Gender Hurts: A Feminist Analysis of the Politics of Transgenderism. Routledge. https://doi.org/10.4324/9781315778266

Jenkins, Katharine (2016). Amelioration and Inclusion: Gender Identity and the Concept of Woman. Ethics, 126(2), 394-421. https://doi.org/10.1086/683535

Kapusta, Stephanie J. (2016). Misgendering and its Moral Contestability. Hypatia, 31(3), 502-519. https://doi.org/10.1111/hypa.12259

Koyama, Emi (2006). Whose Feminism Is It Anyway? The Unspoken Racism of the Trans 
Inclusion Debate. In Susan Stryker and Stephen Whittle (Eds.), The Transgender Studies Reader (698-705). Routledge.

Lester, CN. (2017). Trans Like Me: A Journey for All Of Us. Virago.

Lugones, María (2003). Pilgrimages/Peregrinajes: Theorizing Coalition Against Multiple Oppressions. Rowman \& Littlefield.

McKitrick, Jennifer (2015). A Dispositional Account of Gender. Philosophical Studies, 172(10), 2575-2589 https://doi.org/10.1007/s11098-014-0425-6

Mikkola, Mari (2016). The Wrong of Injustice: The Role of Dehumanization in Feminist Philosophy. Oxford University Press. https://doi.org/10.1093/acprof:o so/9780190601072.001.0001

Namaste, Vivian (2000). Invisible Lives: The Erasure of Transsexual and Transgendered People. University of Chicago Press.

Prosser, Jay (1998). Second Skins: The Body Narratives of Transsexuals. Columbia University Press.

Scheman, Naomi (1997). Queering the Center by Centering the Queer: Reflections on Transsexuals and Secular Jews. In Diana T. Meyers (Ed.), Feminists Rethink the Self (124-162). Westview Press.

Serano, Julia (2016). Whipping Girl: A Transsexual Woman on Sexism and the Scapegoating of Femininity (2nd ed.). Seal Press.

Stone, Sandy (2006). The Empire Strikes Back. In Susan Stryker and Stephen Whittle (Eds.), The Transgender Studies Reader (221-235). Routledge.

Stryker, Susan (1994). My Words to Victor Frankenstein Above the Village of Chamounix: Performing Transgender Rage. GLQ: Gay and Lesbian Quarterly 1, 237-254. 